\title{
Hypofractionated Postoperative Radiation Therapy for Breast Cancer - Do we Need More Evidence or Adapted Reimbursement Policies?
}

Monica-Emilia Chirilă ${ }^{1}$, Ivica Ratosa ${ }^{2,3}$, Gustavo Nader Marta ${ }^{4,5}$, Philip Poortmans $^{6,7}$

${ }^{1}$ Amethyst Radiotherapy Centre, Cluj-Napoca, Romania

${ }^{2}$ Division of Radiation Oncology, Institute of Oncology Ljubljana, Ljubljana, Slovenia

${ }^{3}$ Faculty of Medicine, University of Ljubljana, Ljubljana, Slovenia

${ }^{4}$ Department of Radiation Oncology - Hospital Sírio-Libanes, Sao Paulo, Brazil

${ }^{5}$ Latin American Cooperative Oncology Group, Brazil

${ }^{6}$ Department of Radiation Oncology, Iridium Netwerk, Wilrijk-Antwerp, Belgium

${ }^{7}$ University of Antwerp, Faculty of Medicine and Health Sciences, Wilrijk-Antwerp, Belgium

Corresponding Author: Monica-Emilia Chirilă e-mail: monica.emilia.chirila@gmail.com

\section{Abstract}

More than 10 years ago, two pivotal trials, the Ontario Clinical Oncology Group trial and START B trial, firmly established that hypofractionated radiation therapy (RT) of 40-42.5 Gy in 15-16 fractions over 3 weeks after breast conserving surgery or mastectomy results in similar rates of local recurrence and normal tissue effects. This led to a new standard for postoperative whole breast and chest wall RT. Further trials confirmed these findings and show that hypofractionated RT can also be applied for other indications, including regional nodal RT and for ductal carcinoma in situ (DCIS). More recently, a so-called ultra-fractionation trial demonstrated that 26 Gy in 5 fractions over 1 week was non-inferior to $40 \mathrm{~Gy}$, in 15 fractions in 3 weeks for local recurrence at 6 years and that late effects were similar between fractionation schedules being a treatment option for most patients with early breast cancer. Several countries and departments are now adopting hypofractionated schedules as a new standard for breast, chest wall or partial breast RT. In addition to the improvement in convenience and reduction in resources required, hypofractionated RT offers important benefits with respect to acute and late toxicity that can improve the quality of life of patients receiving breast $R T$.

Keywords: breast cancer, radiotherapy, radiation therapy, fractionation. 


\section{Background}

Postoperative radiation therapy (RT) for breast cancer reduces the locoregional relapse rate and increases survival rates, as has been shown in systematic reviews and meta-analyses of prospective trials [1].

Conventionally fractionated (CF) whole breast RT (WBRT) (50-50.4 Gy/ 25-28 fractions over 5-6 weeks) was based on the assumption that it maximizes tumour control while minimizing normal-tissue injury, and it was used for decades as gold-standard. Early studies of hypofractionation (HF) in breast cancer caused high rates of late sideeffects, due to inaccuracies of the radiobiological models, dose calculation, and treatment delivery [2].

\section{Clinical data}

\section{Moderately hypofractionated RT}

More recent studies, starting with the $90 \mathrm{~s}$, implemented moderately hypofractionated whole breast radiation therapy (HF-WBRT), in which the radiobiological equivalence was achieved by using fractions (fr) of less than 3 Gy and a lower total dose. Nine randomized phase III trials, including more than 12,000 patients with breast cancer reported encouraging results regarding the efficacy and safety of HF. Six of them included only patients with breast-conserving surgery, one was designed exclusively for post-mastectomy RT, and two studies included both these categories of patients [3-10].

The Royal Marsden Hospital and Gloucestershire Oncology Centre study included 1,410 patients who had T1-3 N0-1 M0 breast cancer with a maximum of one involved node and who were at least 50 years old. Based on the higher and lower estimated $\alpha / \beta$ ratio, the calculated dose schedules to be isoeffective with $50 \mathrm{~Gy} / 25 \mathrm{fr}$ were $39 \mathrm{~Gy} / 13 \mathrm{fr}$ and $42.9 \mathrm{~Gy} / 13 \mathrm{fr}$, respectively. The local recurrence rate at 10 years was $12.1 \%, 14.8 \%$, and $9.6 \%$, respectively, with no significant difference when comparing either of the CF-WBRT groups with the HF-WBRT group. The side effects were limited in all groups, but the $42.9 \mathrm{~Gy} / 13$ fr was shown to have a higher effect on normal tissues when compared to $50 \mathrm{~Gy} / 25$ fr [6]. This was the reason for which in the UK START A the dose was reduced to 41.6 $\mathrm{Gy} / 13 \mathrm{fr}$. The other arms received the previously tested dose of $39 \mathrm{~Gy} / 13 \mathrm{fr}$ and the CF-WBRT of $50 \mathrm{~Gy} / 25 \mathrm{fr}$, respectively. From a total of 2,236 patients included in this study, 336 (15\%) underwent mastectomy, and had similar inclusion criteria, regarding the staging. At 10-year follow-up, there was no significant difference in loco-regional relapse between the 3 arms (it was $5.6 \%$ in the $41.6 \mathrm{~Gy} \mathrm{HF}$ group, $8.1 \%$ in the $39 \mathrm{~Gy} \mathrm{HF}$ group, and $6.7 \%$ in the CF group, respectively). Long term side-effects were significantly reduced for $39 \mathrm{~Gy}$ as compared to the patients treated with $50 \mathrm{~Gy}$, but there were no significant differences between patients who received $50 \mathrm{~Gy}$ and $41.6 \mathrm{~Gy}$.

The UK START B trial included patients having the same stage as UK START A, both conservative and radical surgery, and had only two arms: the CF and 40.05 in 15 daily 
fractions, delivered over 3 weeks. Some of the patients had a boost of $10 \mathrm{~Gy}$ in $5 \mathrm{fr}$. Like in the UK START A trial, the loco-regional recurrence did not significantly differ between the two arms (5.5\% for CF and $4.3 \%$ for the 40.05 Gy HF group), and this time, the HF group had an even lower percentage for some of the normal tissue effects such as breast edema, telangiectasia, and breast shrinkage, while the others did not differ. The START trials showed that the $\alpha / \beta$ ratio for both breast cancer and late reacting normal tissues appears similar, which would not translate to any advantage in using conventional, 2 Gy per fraction schedules [3,7].

Another trial that included patients with breast cancer who received WBRT after breast-conserving surgery, was the Ontario Clinical Oncology Group trial. It randomized 1,234 women, stage T1-2 NO M0, who received either CF-WBRT $50 \mathrm{~Gy} / 25 \mathrm{fr}$, either HF-WBRT 42.56 Gy/16 fr. At 10 years, there was no significant difference in local relapse (6.7\% vs $6.2 \%)$, overall survival $(84.4 \%$ vs $84.6 \%$ ), or cosmetic outcome, which was good or excellent for $71.3 \%$ and $69.8 \%$, respectively [8].

The MD Anderson Cancer Center Trial included 287 patients, with stage 0-II breast cancer, after breast-conserving surgery, receiving the same fractionation schedules as the Ontario Clinical Oncology Group trial (50 $\mathrm{Gy} / 25 \mathrm{fr}$ vs $42.56 \mathrm{~Gy} / 16 \mathrm{fr})$. The patients in the CF-WBRT group received a boost of 10-14 Gy (in 5 or 7 fractions, respectively), and those in the HF-WBRT group received 10-
12.5 Gy (in 4 or 5 fractions, respectively). Significantly higher acute side effects (hyperpigmentation, breast pain, acute dermatitis, fatigue, and pruritus) were reported in the CF-WBRT group than in the HF-WBRT group. Grade 2 or higher acute side effects and the 3-year poor cosmetic outcomes were much less frequent in the HFWBRT group [9].

More advanced breast cases (stages pT3-4 pN2-3), treated with mastectomy, were included in the Beijing trial. This time, the supraclavicular and level 3 lymph nodes were irradiated along with the chest wall, using either CF schedule (50 Gy/25 fr), either HF schedule (43.5 Gy/15 fr). The trial randomized 820 patients, having local control as the primary endpoint. The 5 year follow-up results for loco-regional relapse were similar between the two groups $(8.1 \%$ vs $8.3 \%$ ). Grade 3 acute skin toxicity was significantly lower in the HF group, and no other acute or late toxicities differed between the two arms [11].

Data from three clinical trials, including patients with early breast cancer or ductal carcinoma in situ (DCIS) were published in 2020 and are reassuring: there was no difference in the local recurrence rates between CF-WBRT and HF-WBRT arms with or without tumor bed-boost $[4,5,10]$. In the BIG 3-07/TROG 07.01 trial, investigators found improved local recurrence rates with the addition of tumor bed boost for patients with non-low risk DCIS, irrespective of the fractionation schedule [10]. Overall, there were no significant differences in the rates of 
acute or late tissue effects in the CF-WBRT compared to HF-WBRT groups, except that some of the acute toxicities were even less frequent in the HF-WBRT group [4,5].

\section{Ultra-fractionation}

FAST Forward trial (Phase III, noninferiority) tested $40 \mathrm{~Gy} / 15 \mathrm{fr}$ in 3 weeks vs $27 \mathrm{~Gy} / 5 \mathrm{fr}$ in one week vs $26 \mathrm{~Gy} / 5 \mathrm{fr}$ in one week. It included 4,096 patients, either breast conservation or mastectomy being eligible. After a median follow-up of 71.5 months, the local recurrence at 5 years was non-inferior for the 1-week schedules and the normal tissue effect was not worse for the 26 Gy schedule compared to the 40 Gy schedule [12,13].

Ten-year results from the FAST Trial (CRUKE/04/015; Phase III), evaluating 50 $\mathrm{Gy} / 25 \mathrm{fr}$ vs once-weekly 5-fr schedules (30 Gy/ $5 \mathrm{fr}$ or $28.5 \mathrm{~Gy} / 5 \mathrm{fr}$ ), delivered to the whole breast for patients with stage pT1-2 pNO breast cancer demonstrated higher risks for normal tissue effects when $50 \mathrm{~Gy} / 25$ $\mathrm{fr}$ was compared to $30 \mathrm{~Gy} / 5 \mathrm{fr}$. On the other hand, there was no difference in the rates for any moderate or marked physicianassessed side effects, including breastshirnkage, induration, teleangiectasia, edema, comparing conventional $50 \mathrm{~Gy} / 25 \mathrm{fr}$ vs 28.5/5 fr Gy once-weekly schedule [14].

A summary of the studies discussed above, can be found in Table 1.

\section{Radiobiology}

The breast cancer HF schedules are supported also from the radiobiological point of view, by the equivalent doses calculated using a broad range of $\alpha / \beta$ values for normal tissue and breast cancer. The reduced total dose of $40 \mathrm{~Gy} / 15$ fractions leads to a relative sparing of normal tissues, which even increases proportionally for lower dose levels. On the basis of an $\alpha / \beta$ value of $2.7 \mathrm{~Gy}$ (from the START trials), the $40 \mathrm{~Gy} / 15 \mathrm{fr}$ schedule is isoeffective to $45.7 \mathrm{~Gy}$ in $2.0 \mathrm{~Gy}$ - equivalents [14]. The non-inferior local control can be explained by the effect that shortened overall treatment time has on tumour cell proliferation. The START triallists estimated that between 3 and 5 weeks of treatment, 0.6 Gy per calendar day could be lost [15]. In the FAST trial, change in photographic breast appearance gave an unadjusted $\alpha / \beta$ estimate of $2.7 \mathrm{~Gy}$ (1.5 to 3.9) and physician-assessed normal tissue effects gave an unadjusted $\alpha / \beta$ estimate from 1.6 Gy (breast induration) to $3.1 \mathrm{~Gy}$ (telangiectasia). Using an $\alpha / \beta$ of $2.7 \mathrm{~Gy}$, the isoeffect doses expressed in 2.0-Gy equivalents for $30 \mathrm{~Gy}$ and $28.5 \mathrm{~Gy}$ in 5 fractions were approximately $56 \mathrm{~Gy}$ and $51 \mathrm{~Gy}$, respectively, and the once-weekly 5 -fraction schedule (28 Gy total dose, 95\% confidence interval, $\mathrm{Cl}, 26-30)$ was estimated to be isoeffective with $50 \mathrm{~Gy} / 25 \mathrm{fr}$ [14]. The $\alpha / \beta$ estimates from FAST are compatible with the START-A trial analysis, which generated estimates around 3-4 Gy for late normal tissue effects in the breast [7]. 
Table 1. Randomized controlled trials on Moderate Hypofractionation and Ultra-Hypofractionation in postoperative Radiation therapy for Breast Cancer

\begin{tabular}{|c|c|c|c|c|c|c|c|c|c|c|c|}
\hline & \multirow{2}{*}{$\begin{array}{l}\text { Number } \\
\text { of } \\
\text { patients }\end{array}$} & \multicolumn{2}{|c|}{ Inclusion } & \multirow{2}{*}{$\begin{array}{l}\text { Median follow- } \\
\text { up - years } \\
\text { (range) }\end{array}$} & \multicolumn{2}{|c|}{ Type of surgery $\mathrm{N}(\%)$} & \multirow{3}{*}{$\begin{array}{c}\text { Chemotherapy } \\
\mathrm{N}(\%)\end{array}$} & \multirow{3}{*}{$\begin{array}{c}\text { Endocrine } \\
\text { therapy } \\
N(\%)\end{array}$} & \multirow{3}{*}{$\begin{array}{l}\text { Chemotherapy } \\
\text { and endocrine } \\
\text { therapy } \mathbf{N}(\%)\end{array}$} & \multirow{3}{*}{$\begin{array}{l}\text { Boost } \\
N(\%)\end{array}$} & \multirow{3}{*}{$\begin{array}{c}\text { Regional } \\
\text { nodal } \\
\text { irradiatior } \\
\mathrm{N}(\%)\end{array}$} \\
\hline & & Years & Criteria & & $\begin{array}{c}\text { Breast- } \\
\text { conserving } \\
\text { surgery }\end{array}$ & Mastectomy & & & & & \\
\hline \multicolumn{7}{|c|}{ Moderate Hypofractionation } & & & & & \\
\hline RMH/GOC611 & 1410 & $1986-1998$ & T1-3 N01 Mo & $9.7(7.8-11.8)$ & $1410(100)$ & 0 & $196(14)$ & $918(65.1)$ & 156 (11.1) & $1051(75)$ & $290(21)$ \\
\hline START A & 2236 & 1998-2002 & T1-3 NO-1 MO & $9.3(8.0-10.0)$ & $1900(85)$ & $336(15)$ & $793(35)$ & $1210(54.1)$ & $548(24.5)$ & $1152(61)$ & $318(14)$ \\
\hline START B & 2215 & 1999-2001 & T1-3 No-1 MO & $9.9(7.5-10.1)$ & $2038(92)$ & $177(8)$ & $491(22)$ & $1592(71.9)$ & 336 (15.2) & $875(43)$ & $161(7)$ \\
\hline ocoG514 & 1234 & 1993-1996 & T1-2 NOMO & $12.0^{*}$ & $1234(100)$ & 0 & $136(11)$ & $516(41.8)$ & NA & 0 & 0 \\
\hline Beijing Trial & 820 & 2008-2016 & T3-T4 N2-3 M0 & $4.9(3.7-6.8)$ & 0 & $820(100)$ & $820(100)$ & $620(75.6)$ & NA & 0 & $820(100)$ \\
\hline DBCG HYPO & 1882 & 2009-2014 & $\begin{array}{l}\text { pTis-T2 No- } \\
\text { N1(mic) M0 }\end{array}$ & $7.3^{*}$ & $1882(100)$ & 0 & $668(36)$ & $560(29.7)^{*}$ & NA & $426(23)$ & 0 \\
\hline NCT01413269 & 729 & 2010-2015 & T1-2 No-2a MO & $6.1^{*}$ & $729(100)$ & 0 & $477(65)$ & $238(32.7)$ & $358(49.1)$ & $\begin{array}{c}732 \\
(99.7)\end{array}$ & $28(3.9)$ \\
\hline $\begin{array}{c}\text { BIG 3-07TROG } \\
07.01\end{array}$ & 1608 & 2007-2014 & pTis No MO & $6.6^{*}$ & $1608(100)$ & 0 & 0 & $225(14)$ & 0 & $803(50)$ & 0 \\
\hline \multicolumn{12}{|c|}{ Ultra-Hypofractionation } \\
\hline $\begin{array}{l}\text { FAST } \\
\text { (CRUKEI } \\
04 / 015)\end{array}$ & 915 & 2004-2007 & PT1-2 NO MO & 3.1 & $915(100)$ & 0 & 0 & $809(88.4)$ & 0 & 0 & 0 \\
\hline $\begin{array}{l}\text { FAST- } \\
\text { Forward }\end{array}$ & 4096 & 2011-2014 & PT1-3 N0-1 MO & 6 & $3832(93.6)$ & $264(6.4)$ & $1447(35.3)$ & $3512(96.2)$ & NA & $\begin{array}{l}1011 \\
(24.7)\end{array}$ & $0^{* *}$ \\
\hline
\end{tabular}

RMH/GOC = Royal Marsden Hospital/Gloucestershire Oncology Centre; OCOG = Ontario Clinical Oncology Group; START = Standardization of Breast Radiotherapy Trial; DBCG = Danish Breast Cancer Group; * The information was not available in the original publication; ${ }^{* *}$ Lower axilla included in standard tangential fields to breast/chest wall irradiation was allowed; $N A=$ data not available; $¥=$ At least $29 \%$ of all patients included in the study received endocrine therapy; in the original publication endocrine data were reported only for the Denmark cohort, within the Denmark cohort 560/1489 (37.6\%) patients received endocrine therapy.

In the FAST FORWARD Trial, the unadjusted $\alpha / \beta$ value estimate for any moderate/marked physician-assessed normal tissue effect was $1.7 \mathrm{~Gy}(95 \% \mathrm{Cl} 1.2-2.3)$, for the photographic endpoint was $1.8 \mathrm{~Gy}$ (95\% Cl 1.1-2.4) and for patient reported change in breast apperance was $2.3 \mathrm{~Gy}$ $(95 \% \mathrm{Cl} 1.8-2.9)$, resulting in $\mathrm{EQD}_{2}-$ equivalents estimate of $46.1-47.1$ Gy for 40 $\mathrm{Gy} / 15 \mathrm{fr}, 48.2-51.6 \mathrm{~Gy}$ for $27 \mathrm{~Gy} / 5 \mathrm{fr}$ and $48.3-45.2$ Gy for $26 \mathrm{~Gy} / 5 \mathrm{fr}[12]$.

\section{Discussion points}

The HF schedules are not uniformly implemented, and many clinicians still prefer to use $C F$, although the evidence, regarding the efficacy and safety of the moderately hypofractionated schedules is accumulating. The reasons could be related to concerns regarding possible late side-effects on patients who were underrepresented in most of the trials, or reimbursement-related issues $[16,17]$.

At the 2019 St Gallen/Vienna conference, there was no clear consensus between the panelists regarding hypofractionation [18], but the recently updated ESMO guidelines recommend moderate $\mathrm{HF}$ for routine postoperative RT of breast cancer. Careful monitoring of patients not fitting into the inclusion criteria of the published studies treated with HF was recommended [19]. 


\subsection{Chest wall and regional lymph nodes}

One of the categories in which some of the doctors seem to be reluctant to prescribe HF schedules is represented by the patients who were previously treated with modified radical mastectomy and lymph node dissection.

The results of the United States National Cancer Database study demonstrated that between 2004 and 2014 the use of HF postmastectomy RT of the chest wall (with or without the regional lymph nodes) represented $1.1 \%$ of all patients. For this category of patients who were treated with mastectomy, the European survey reported HF preference ranged from $0 \%$ (in Slovakia, Ukraine, and Lithuania) to $100 \%$ (in Netherlands, Belgium, UK, and Ireland). Overall, it was used by $37.6 \%$ practicing in academic hospitals and by $25.4 \%$ from those from nonacademic clinics or departments [16].

The START A and B trials included $14.7 \%(n=864)$ patients who received lymphatic radiation, and $8.5 \% \quad(n=513)$ who underwent mastectomy. There were no statistically significant differences in the cumulative local recurrence rates after mastectomy or breast-conserving surgery, irrespective of being evaluated by patients or physicians [7]. The Beijing trial reported similar results, in patients with higher stage breast cancer and treated with 3DCRT [11]. In the recent second trial from China, evaluating WBRT with (small proportion, 3$4 \%$ ) or without nodal irradiation, the authors demonstrated that HF-WBRT, followed by the HF-boost had a similar local recurrence rate without increased rates of acute or late toxicity, compared to CF-WBRT [5].

The toxicity related to fractionation to the regional nodal areas is not considered as a reason of concern for several other types of cancer. For example, locally advanced head and neck cancer patients are treated with high biological equivalent doses of radiation (60-70 Gy), even concomitant with chemotherapy, the fractionation schedules being independent of the anatomical subsite [20].

An additional concern was raised when HF RT was used before or after breast reconstruction was done, using implants or autologous tissue. Although there is no extensive data on this topic, a phase II prospective trial including 69 stage II-III breast cancer patients should be mentioned. The patients were treated with mastectomy and postoperative HF RT (36.63 Gy over 11 days) to the chest wall and the regional lymph nodes, followed by an optional boost to the mastectomy scar of $13.32 \mathrm{~Gy}$ in 4 fractions [21]. Temporary expanders or implants were used for breast reconstruction in 41 patients. The relapse-free survival rate was $89.2 \%$ for all patients after 3 years of follow-up. The expanders were removed due to infection in 3 of the patients before RT. The rate of additional surgical correction was $8 \%$, and $24 \%$ for the implant failure. Similar complication rates were observed after conventional RT in patients with breastreconstruction [22]. Since most breastrelated radiation toxicities (skin retraction, 
fibrosis, and breast shrinkage) seem to be less frequent and less severe in patients who were treated with HF RT, we can expect that a homogenous dose distribution provided by moderate $\mathrm{HF}$ to have outcomes at least as good as CF. The ESTRO-ACROP guidelines allow reducing the irradiated volume by limiting the target to the zones at risk, which is expected to lower the side effects, too [23] . Reduced toxicity by delivery of HF RT with methods that improve the homogeneity of dose distribution (IMRT/VMAT) is currently being investigated for patients with the reconstructed chest wall.

\subsection{Boost fractionation}

Even if most patients in the HF clinical trials used a CF boost of 5-8 fractions of 2 Gy, there are teams from the UK, the Netherlands, and Italy that have many years of experience with HF boost schedules leading to good results [24].

Tumor bed boost $(n=388)$ vs no boost $(n=389)$ following HF-WBRT in patients with non-low risk DCIS was investigated in the BIG 3-07/TROG 07.01 trial. For the whole group of investigated patients $(n=1,608)$, including patients who received CF-WBRT with or without boost, the 5-year local recurrence rates were $3 \%$ in the boost group and $7 \%$ in the non-boost group [10]. However, cosmetic status was worse with tumor bed boost than with no boost across all time points - at the end of treatment and were persisting at 24 months. In addition, CF-WBRT was associated with worse body image than HF-WBRT at the end of treatment [25].

The feasibility of the utilization of the sequential tumor bed boost in the setting of ultrahypofractionated schedules was demonstrated in the FAST FORWARD trial, where a sequential tumor bed boost was allowed for the patients under 40 years of age and for those aged 40-49 years and adverse tumor characteristics (grade 3 tumors with or without lymphovascular space invasion). Sequential tumor bed boost dose, delivered in $10 \mathrm{~Gy} / 5 \mathrm{fr}$ (76-81\%) and $16 \mathrm{~Gy} / 8 \mathrm{fr}(19-23.4 \%)$, was received by about $25 \%$ of patients in each of the three treatment arms [12].

The simultaneously integrated boost (SIB) can be implemented by adding several fractions (5, mostly) and without increasing the maximum fraction size. Postoperative RT with SIB has a potential to further shorten the treatment time without compromising clinical outcomes and is under intensive clinical investigation. The IMPORT High trial included more than 2,600 patients and integrated the boost while maintaining a constant number of fractions. The HF SIB is safe in terms of 3-year toxicity and correlated adverse effects with increasing dose, but not with fraction size [26]. An analysis of the tumour factors that might be predictive of response to HF RT did not find a correlation with tumour grade, molecular subtype, and hypoxia, suggesting that patients of all grades and molecular subtypes may benefit from these protracted schedules [27].

A small, multicenter single arm prospective phase II study from Germany 
included 149 patients with breast cancer, receiving $40 \mathrm{~Gy} / 16 \mathrm{fr}$ to the whole breast and $48 \mathrm{~Gy} / 16$ fr to the tumor bed demonstrated encouraging results in terms of acute toxicity. Acute skin reaction grade $\geq 2$ occurred in $14.7 \%(95 \% \mathrm{Cl} 9.8-21.4)$ of patients [28].

In the HYPOSIB randomized trial (ARO 2013-05, NCT02474641, phase III, multicentric, non-inferiority), comparing standard postoperative WBRT (50.4 Gy/28 fr plus sequential boost 10-16 Gy/5-8 fr) and HF-WBRT with a SIB (40 Gy/16 fr to the whole breast and 48/16 fr to the tumor bed), 2,324 patients with breast cancer were recruited from 2015 to 2019 [29]. Preliminary safety data, with a median follow-up of 28 months demonstrated a comparable number of all adverse events (1741 vs 1657) and severe adverse events ( 80 vs 72 ) in both arms. Maximal rates of grade $\geq 2$ acute skin reactions were $23.9 \%$ (week 6 ) and $15.8 \%$ (week 4) for the control and experimental arm, respectively [30].

The UK IMPORT HIGH trial (CRUK/06/003, randomised, multi-centre, phase III trial) compared $40 \mathrm{~Gy} / 15 \mathrm{fr}$ plus 16 Gy/8 fr sequential boost, to other 2 arms. Both arms had $36 \mathrm{~Gy} / 15 \mathrm{fr}$ to the whole breast and 40 Gy to the partial breast. Test Group 1 received $48 \mathrm{~Gy} / 15 \mathrm{fr}$ SIB and Test Group 2 received $53 \mathrm{~Gy} / 15 \mathrm{fr}$ SIB on the tumour bed. The study included early stage breast cancer with a higher risk of local relapse and the treatment was delivered by IMRT. Preliminary results reported data acquired from 2,617 women with a median age of 49 years. At 3 years, rates of moderate/marked adverse events were similar between the groups receiving IMRT sequential and concomitant boost, respectively [26].

Additional research, evaluating higher doses per fraction (> $2.0 \mathrm{~Gy}$ ) is underway. The final results of the three phase III trials, including the UK IMPORT HIGH trial, the RTOG 1005 (NCT01349322) and the SKAGEN trial 1 (NCT02384733), are excitedly awaited to show if dose escalation by modern treatment planning using either 3DCRT-SIB or IMRT/VMAT-SIB could improve overall treatment results $[31,32]$.

The results of the IMRT-MC2 Trial (Phase III, noninferiority, $n=502$ ), evaluating CF 3DCRT (50.4 Gy/28 fr) with sequential boost (16 Gy/8 fr) vs conventionally fractionated IMRT-SIB $(50.4 \mathrm{~Gy} / 28 \mathrm{fr}$, SIB $64.4 \mathrm{~Gy} / 28 \mathrm{fr}$ ) are also adding to the evidence of the efficacy and safety of the integrated tumor dose approach. At 2-years, both treatment arms demonstrated excellent local control and equivalent objective or subjective cosmetic assessment [33].

\subsection{Late effects on the organs at risk} and the added toxicity of chemotherapy

Some clinicians express their doubts regarding a possible underestimation of late toxicities on lung, heart, and nervous tissue, because of the long necessary follow-up. It should be mentioned that the only patient who received RT to the breast and supraclavicular fossa area developed a mild plexopathy in the START trials had a 
suspected genetic disorder. Using $\alpha / \beta$ ratios of $3 \mathrm{~Gy}$ and $1.5 \mathrm{~Gy}$, the $40 \mathrm{~Gy}$ in 15 fractions (START B trial) HF regimen is estimated at an equivalent $E Q D_{2}$ Gy biological dose of $45.42 \mathrm{~Gy}$ and $47.72 \mathrm{~Gy}$ to the brachial plexus [34].

Other radiation oncologists are pointing out that only a limited number of patients enrolled in the HF clinical trials received chemotherapy (i.e., $11 \%, 35 \%$, and $22 \%$ of patients in the Ontario Clinical Oncology Group, START A, and START B trials, respectively) [7]. However, the MD Anderson trial and Beijing trial (with the temporary reserve of a relatively short follow-up), reported satisfactory toxicity results in patients receiving standard chemotherapy, including anthracycline and taxane- or anthracycline-based regimens $[9,11]$. Similarly, in an aforementioned study by Wang et al., the receipt of current-era chemotherapy was evenly distributed in the CF-WBRT arm (up to $64 \%$ patients) and in the HF-WBRT arm (up to $66 \%$ patients). Of the 477 patients, $350(73.4 \%)$ received chemotherapy followed by radiotherapy, and 127 (26.6\%) received radiotherapy followed by chemotherapy [5]. Regarding the rates of ischemic heart disease and lung fibrosis, they are very low $(<2 \%)$, and the dose received by these organs at risk is expected to get even lower in the context of the wider availability of high conformal techniques and image-guided RT [35,36].

\section{Technical considerations}

Dose inhomogeneity can determine certain regions to receive a higher dose, which leads to the "double trouble" of both higher dose per fraction and higher total dose. In the case of HF, the equivalent dose in $2 \mathrm{~Gy}$ fractions is higher relative to $\mathrm{CF}$, this situation being referred to as "triple trouble" [37]. This effect should not be present in the current HF schedules for hotspots up to $107 \%$, thanks to the moderately increased fraction size in the context of a consistent decrease in total dose [3].

The impact of dose inhomogeneity was retrospectively evaluated on 390 datasets from patients included in the FAST Forward trial. The risk of change in breast appearance at 2 years follow-up did not differ in the $40 \mathrm{~Gy}$ control arm and the HF schedules (26 and $27 \mathrm{~Gy}$, respectively, in 5 fr) after adjusting for breast size and surgical deficit [38].

Except for the obvious improvements in $\mathrm{RT}$ technological aspects related to planning and delivery, other essential factors are the accuracy in defining target volumes as recommended by cooperative groups or societies [23] and the accuracy of daily setup and positioning.

\section{Economic considerations}

Treatment protocols that involve fewer fractions decrease the caseload at radiation therapy units and free up resources for more patients, reducing the waiting time. It also decreases indirect costs associated with 
outpatient's daily traveling and also the productivity loss for those who still work during treatment [39].

On the other hand, many of the reimbursement systems are based on payment/fraction. The financial impact of using HF for breast cancer was recently analyzed by an international consortium, taking in account data from 13 countries (Denmark, France, Italy, the Netherlands, Spain, UK; Canada, USA, Brazil, Australia, Israel, Taiwan). In $77 \%$ of the participant countries, a financial loss would occur by applying the HF schedule. In $60 \%$ of situations when a revenue loss would occur, it would be $30-40 \%$ per patient. Since patients with breast cancer represent about a quarter of the patients treated in most radiation oncology departments, this economic impact cannot be neglected [40]. In the EBCC Manifesto, a calculation was presented for 1 single example, showing that the introduction of moderate HF, combined with restricting the indications for a boost to the primary tumour bed, are financially not viable for any radiation oncology department under these circumstances [41].

\section{General discussion}

Despite the high supporting evidence and the significant financial benefits, HF RT for breast cancer has not been generally adopted in many countries. One of the reasons is probably related to a reluctance to apply it for certain patient groups.

Almost $70 \%$ of the radiation oncologists who participated in the European survey mentioned at least one factor that they take into account when deciding on choosing HF over CF for breast cancer. The age of the patient was important for more than half of the respondents, followed by the necessity of regional nodal irradiation, (especially the internal mammary node chain) breast cancer stage, implant-based reconstruction, dose to organs at risk, breast laterality, surgical margins, dose to OARs, flap-based reconstruction and dose inhomogeneity. All these elements were considered as decision-influencing by at least $20 \%$ of the respondents. Breast cancer grade, surgical margins, breast laterality, molecular subtype, financial issues, and use of "high tangents" were important only for few radiation oncologists (up to $15.9 \%$ )

Participants practicing in Western European Countries or Academic hospitals, and those dedicating more than $50 \%$ of their time to treating breast cancer patients, were significantly less influenced in their acceptance of HF RT by these factors [16].

More information on this topic will be brought by the current ongoing trials (e.g., NCT02690636, NCT02700386, NCT02958774, NCT03127995) and will eventually answer the existent doubts of more reluctant radiation oncologists. However, even then and in the context of solid scientific data, the reimbursement systems have to be adapted, so the clinicians will not have to deal with the hard decision of prescribing a treatment that they know it is effective, safe, and logistically convenient, being aware at the same time 
that they are causing severe financial losses to the department.

In general, health policy decision-makers and funders do not have sufficient clinical insights and knowledge to guide more adapted reimbursement policies, and possibly do not realize that a proactive approach can provide strong incentives for the clinical practice. Unfortunately, too often, the reimbursement practices are not aligned with treatment guidelines, varying significantly between countries, regions, and even institutions.

Even if a perfect overlapping of the treatment costs and treatment reimbursement cannot be achieved, adapting the policies according to the complexity of the treatment and not on the number of fractions, will improve the access to quality healthcare. Especially in the countries with limited resources, this effect is even more visible, by also decreasing the waiting time for the treatment initiation [42].

This topic is gaining more visibility by the official position of experts and professional organizations and patient advocates representatives, pleading for better use of the existent funding [41].

\section{Abbreviations}

$\mathrm{RT}$ - radiation therapy

DCIS - ductal carcinoma in situ

CF - Conventionally fractionated

WBRT - whole breast RT

HF - hypofractionation

HF-WBRT - hypofractionated whole breast radiation therapy

EBCC - European Breast Cancer Confere

\section{Conclusions}

Moderate hypofractionated postoperative radiation therapy for breast cancer is supported by current evidence and is safe and effective, irrespective of patient-, tumour- and treatment-related factors. More recent evidence even strongly supports the use of ultra-hypofractionated postoperative breast radiation therapy, 26 Gy delivered in 5 fractions in 1 week or 28.5 Gy in 5 fractions over 5 weeks. These could be considered as an alternative schedule for whole breast, chest wall and PBI, with similar rates of local control normal tissue toxicity. There is currently a significant variation between countries in implementing it and the reasons are both subjective and objective, but the pandemic helped convincing its use to limit the viral transmission risks. The personal reluctance of some radiation oncologists to prescribe HF schedules for certain patients can arise from insufficient information and reimbursement policies that do not encourage their implementation 


\section{Statements:}

Authors' contributions: MEC and PP planned the analysis. GNM, MEC and IR collected the data and performed the analysis, CME and IR wrote the manuscript, GNM and PP reviewed the manuscript.

Consent for publication: As the corresponding author, I confirm that the manuscript has been read and approved for submission by all co-authors.

Conflict of interest: All authors declare having no competing interests associated with this publication.

Funding Sources: This research did not receive any specific grant from funding agencies in the public, commercial, or not-for-profit sector.

Statement of Ethics: The accompanying manuscript does not contain any studies carried out by the authors on humans or animals.

\section{References:}

1. McGale P, Taylor C, Correa C, Cutter D, Duane F, Ewertz M, et al. Effect of radiotherapy after mastectomy and axillary surgery on 10-year recurrence and 20-year breast cancer mortality: meta-analysis of individual patient data for 8135 women in 22 randomised trials. Lancet [Internet]. Elsevier Ltd; 2014 [cited 2014 Jul 12];383:2127-35. Available from: http://www.ncbi.nlm.nih.gov/pubmed/24656685

2. Johansson S, Svensson H, Denekamp J. Dose response and latency for radiation-induced fibrosis, edema, and neuropathy in breast cancer patients. Int J Radiat Oncol Biol Phys [Internet]. Int J Radiat Oncol Biol Phys; 2002 [cited 2021 Feb 13];52:1207-19. Available from: https://pubmed.ncbi.nlm.nih.gov/11955731/

3. Marta GN, Coles C, Kaidar-Person O, Meattini I, Hijal T, Zissiadis Y, et al. The use of moderately hypofractionated post-operative radiation therapy for breast cancer in clinical practice: A critical review [Internet]. Crit. Rev. Oncol. Hematol. Elsevier Ireland Ltd; 2020 [cited 2021 Feb 13]. p. 103090. Available from: /pmc/articles/PMC7448956/

4. Offersen B V, Alsner J, Nielsen HM, Jakobsen EH, Nielsen MH, Krause M, et al. Hypofractionated Versus Standard Fractionated Radiotherapy in Patients With Early Breast Cancer or Ductal Carcinoma In Situ in a Randomized Phase III Trial: The DBCG HYPO Trial. J Clin Oncol Off J Am Soc Clin Oncol. United States; 2020;38:3615-25.

5. Wang S-L, Fang H, Hu C, Song Y-W, Wang W-H, Jin J, et al. Hypofractionated Versus Conventional Fractionated Radiotherapy After Breast-Conserving Surgery in the Modern Treatment Era: A Multicenter, Randomized Controlled Trial From China. J Clin Oncol Off J Am Soc Clin Oncol. United States; 2020;38:3604-14.

6. Owen JR, Ashton A, Bliss JM, Homewood J, Harper C, Hanson J, et al. Effect of radiotherapy fraction size on tumour control in patients with early-stage breast cancer after local tumour excision: long-term results of a randomised 
trial. Lancet Oncol [Internet]. 2006 [cited 2016 Sep 18];7:467-71. Available from: http://www.ncbi.nlm.nih. gov/pubmed/16750496

7. Haviland JS, Owen JR, Dewar JA, Agrawal RK, Barrett J, Barrett-Lee PJ, et al. The UK Standardisation of Breast Radiotherapy (START) trials of radiotherapy hypofractionation for treatment of early breast cancer: 10-year follow-up results of two randomised controlled trials. Lancet Oncol [Internet]. 2013 [cited 2016 Oct 9];14:1086-94. Available from: http://www.ncbi.nlm.nih.gov/pubmed/24055415

8. Whelan TJ, Pignol J-P, Levine MN, Julian JA, MacKenzie R, Parpia S, et al. Long-term results of hypofractionated radiation therapy for breast cancer. N Engl J Med [Internet]. 2010 [cited 2015 Mar 6];362:513-20. Available from: http://www.ncbi.nlm.nih.gov/pubmed/20147717

9. Shaitelman SF, Lei X, Thompson A, Schlembach P, Bloom ES, Arzu IY, et al. Three-Year Outcomes With Hypofractionated Versus Conventionally Fractionated Whole-Breast Irradiation: Results of a Randomized, Noninferiority Clinical Trial. J Clin Oncol [Internet]. American Society of Clinical Oncology; 2018 [cited 2021 Feb 13];36:3495-503. Available from: https://ascopubs.org/doi/10.1200/JCO.18.00317

10. Chua $\mathrm{BH}$, Link E, Kunkler I et al. A randomized phase III study of radiation doses and fractionation schedules in non-low risk ductal carcinoma in situ (DCIS) of the breast (BIG 3-07/TROG 07.01). GS2-04. San Antonio Breast Cancer Symposium (virtual SABCS).

11. Wang SL, Fang H, Song YW, Wang WH, Hu C, Liu YP, et al. Hypofractionated versus conventional fractionated postmastectomy radiotherapy for patients with high-risk breast cancer: a randomised, non-inferiority, open-label, phase 3 trial. Lancet Oncol. Lancet Publishing Group; 2019;20:352-60.

12. Murray Brunt A, Haviland JS, Wheatley DA, Sydenham MA, Alhasso A, Bloomfield DJ, et al. Hypofractionated breast radiotherapy for 1 week versus 3 weeks (FAST-Forward): 5 -year efficacy and late normal tissue effects results from a multicentre, non-inferiority, randomised, phase 3 trial. Lancet [Internet]. Elsevier; 2020 [cited 2020 May 9];6736:1-14. Available from: https://linkinghub.elsevier.com/retrieve/pii/S0140673620309326

13. Brunt AM, Wheatley D, Yarnold J, Somaiah N, Kelly S, Harnett A, et al. Acute skin toxicity associated with a 1-week schedule of whole breast radiotherapy compared with a standard 3-week regimen delivered in the UK FASTForward Trial. Radiother Oncol. Elsevier Ireland Ltd; 2016;120:114-8.

14. Brunt AM, Haviland JS, Sydenham M, Agrawal RK, Algurafi H, Alhasso A, et al. Ten-Year Results of FAST: A Randomized Controlled Trial of 5-Fraction Whole-Breast Radiotherapy for Early Breast Cancer. J Clin Oncol Off J Am Soc Clin Oncol. 2020;38:3261-72.

15. Haviland JS, Bentzen SM, Bliss JM, Yarnold JR, START Trial Management Group. Prolongation of overall treatment time as a cause of treatment failure in early breast cancer: An analysis of the UK START (Standardisation of Breast Radiotherapy) trials of radiotherapy fractionation. Radiother Oncol [Internet]. 2016 [cited 2016 Oct 9]; Available from: http://www.ncbi.nlm.nih.gov/pubmed/27666929

16. Ratosa I, Chirilă ME, Steinacher M, Kozma E, Vojtíšek R, Franco P, et al. Hypofractionated radiation therapy for breast cancer: Preferences amongst radiation oncologists in Europe - Results from an international survey. Radiother Oncol [Internet]. Elsevier Ireland Ltd; 2021 [cited 2021 Feb 13];155:17-26. Available from: https://pubmed.ncbi.nlm.nih.gov/33065187/ 
17. Marta GN, Poortmans P. Moderately hypofractionated breast radiation therapy: is more evidence needed? Lancet Oncol. Lancet Publishing Group; 2019. p. e226.

18. Balic M, Thomssen C, Würstlein R, Gnant M, Harbeck N. St. Gallen/Vienna 2019: A Brief Summary of the Consensus Discussion on the Optimal Primary Breast Cancer Treatment. Breast Care [Internet]. S. Karger AG; 2019 [cited 2021 Feb 13];14:103-10. Available from: https://www.karger.com/Article/FullText/499931

19. Cardoso F, Kyriakides S, Ohno S, Penault-Llorca F, Poortmans P, Rubio IT, et al. Early breast cancer: ESMO Clinical Practice Guidelines for diagnosis, treatment and follow-up. Ann Oncol [Internet]. Elsevier Masson SAS; 2019;30:1194-220. Available from: https://doi.org/10.1093/annonc/mdz173

20. Mendez LC, Moraes FY, Poon I, Marta GN. The management of head and neck tumors with high technology radiation therapy [Internet]. Expert Rev. Anticancer Ther. Taylor and Francis Ltd; 2016 [cited 2021 Feb 13]. p. 99110. Available from: https://pubmed.ncbi.nlm.nih.gov/26568146/

21. Khan AJ, Poppe MM, Goyal S, Kokeny KE, Kearney T, Kirstein L, et al. Hypofractionated postmastectomy radiation therapy is safe and effective: First Results from a prospective phase II trial. J Clin Oncol [Internet]. American Society of Clinical Oncology; 2017 [cited 2021 Feb 13];35:2037-43. Available from: https://ascopubs.org/doi/10.1200/JCO.2016.70.7158

22. Eriksson M, Anveden L, Celebioglu F, Dahlberg K, Meldahl I, Lagergren J, et al. Radiotherapy in implantbased immediate breast reconstruction: Risk factors, surgical outcomes, and patient-reported outcome measures in a large Swedish multicenter cohort. Breast Cancer Res Treat [Internet]. Breast Cancer Res Treat; 2013 [cited 2021 Feb 13];142:591-601. Available from: https://pubmed.ncbi.nlm.nih.gov/24258257/

23. Kaidar-Person O, Vrou Offersen B, Hol S, Arenas M, Aristei C, Bourgier C, et al. ESTRO consensus guideline for target volume delineation in the setting of postmastectomy radiation therapy after implant-based immediate reconstruction for early stage breast cancer. Radiother Oncol [Internet]. Elsevier Ireland Ltd; 2019 [cited 2021 Feb 13];137:159-66. Available from: https://pubmed.ncbi.nlm.nih.gov/31108277/

24. Palumbo I, Mariucci C, Falcinelli L, Perrucci E, Lancellotta V, Podlesko AM, et al. Hypofractionated whole breast radiotherapy with or without hypofractionated boost in early stage breast cancer patients: a mono-institutional analysis of skin and subcutaneous toxicity. Breast Cancer [Internet]. Springer Tokyo; 2019 [cited 2021 Feb 13];26:290-304. Available from: https://pubmed.ncbi.nlm.nih.gov/30341747/

25. King MT, Link EK, Whelan TJ, Olivotto IA, Kunkler I, Westenberg AH, et al. Quality of life after breastconserving therapy and adjuvant radiotherapy for non-low-risk ductal carcinoma in situ (BIG 3-07/TROG 07.01): 2year results of a randomised, controlled, phase 3 trial. Lancet Oncol [Internet]. Lancet Publishing Group; 2020 [cited 2021 Feb 13];21:685-98. Available from: https://pubmed.ncbi.nlm.nih.gov/32203696/

26. Coles C, Griffin C, Kirby A, Haviland J, Titley J, Benstead K, et al. Abstract GS4-05: Dose escalated simultaneous integrated boost radiotherapy for women treated by breast conservation surgery for early breast cancer: 3-year adverse effects in the IMPORT HIGH trial (CRUK/06/003). American Association for Cancer Research (AACR); 2019. p. GS4-05-GS4-05.

27. Bane AL, Whelan TJ, Pond GR, Parpia S, Gohla G, Fyles AW, et al. Tumor factors predictive of response to hypofractionated radiotherapy in a randomized trial following breast conserving therapy. Ann Oncol Off $\mathrm{J}$ Eur Soc Med Oncol. England; 2014;25:992-8. 
28. Krug D, Baumann R, Krockenberger K, Vonthein R, Schreiber A, Boicev A, et al. Adjuvant hypofractionated radiotherapy with simultaneous integrated boost after breast-conserving surgery: results of a prospective trial. Strahlentherapie und Onkol. 2021;197:48-55.

29. Krug D, Vonthein R, Schreiber A, Boicev AD, Zimmer J, Laubach R, et al. Impact of guideline changes on adoption of hypofractionation and breast cancer patient characteristics in the randomized controlled HYPOSIB trial. Strahlentherapie und Onkol [Internet]. 2020; Available from: https://doi.org/10.1007/s00066-020-01730-9

30. Dunst J, Krug D, Schreiber A, Boicev AD, Zimmer J, Laubach R, et al. Patient Reported Experience with Treatment Modalities and Safety of Adjuvant Breast Radiotherapy - First Results of the Randomized HYPOSIB Study. Int J Radiat Oncol [Internet]. Elsevier BV; 2020 [cited 2021 Feb 13];108:S13. Available from: http://www.redjournal.org/article/S0360301620335100/fulltext

31. IMPORT HIGH (Intensity Modulated Partial Organ Radiotherapy) PROTOCOL Randomised trial testing dose escalated intensity modulated radiotherapy for women treated by breast conservation surgery and appropriate systemic therapy for early breast cancer [Internet]. Available from: https://d1ijoxngr27nfi.cloudfront.net/docs/defaultsource/default-document-library/import-high-protocol-mrec-version-7-final-working-copy20140429.pdf?sfvrsn=182f2169_0

32. RTOG 1005 Protocol Information: A Phase III Trial Of Accelerated Whole Breast Irradiation With Hypofractionation Plus Concurrent Boost Versus Standard Whole Breast Irradiation Plus Sequential Boost For EarlyStage Breast Cancer. 2014; Available from: https://www.rtog.org/clinicaltrials/protocoltable/studydetails. aspx?study=1005\&mode=broadcasts $\&$ ptid $=387$

33. Hörner-Rieber J, Forster T, Hommertgen A, Haefner MF, Arians N, König L, et al. Intensity Modulated Radiation Therapy (IMRT) With Simultaneously Integrated Boost Shortens Treatment Time and Is Noninferior to Conventional Radiation Therapy Followed by Sequential Boost in Adjuvant Breast Cancer Treatment: Results of a Large Randomized Phase III Trial (IMRT-MC2 Trial). Int J Radiat Oncol Biol Phys. Elsevier Inc.; 2021;

34. Yarnold J, Bentzen SM, Coles C, Haviland J. Hypofractionated whole-breast radiotherapy for women with early breast cancer: Myths and realities [Internet]. Int. J. Radiat. Oncol. Biol. Phys. Int J Radiat Oncol Biol Phys; 2011 [cited 2021 Feb 13]. p. 1-9. Available from: https://pubmed.ncbi.nlm.nih.gov/20950960/

35. Verbanck S, Hanon S, Schuermans D, Van Parijs H, Vinh-Hung V, Miedema G, et al. Mild Lung Restriction in Breast Cancer Patients After Hypofractionated and Conventional Radiation Therapy: A 3-Year Follow-Up. Int J Radiat Oncol Biol Phys [Internet]. Elsevier Inc.; 2016 [cited 2021 Feb 13];95:937-45. Available from: http://www.redjournal.org/article/S036030161600122X/fulltext

36. Chan EK, Woods R, Virani S, Speers C, Wai ES, Nichol A, et al. Long-term mortality from cardiac causes after adjuvant hypofractionated vs. conventional radiotherapy for localized left-sided breast cancer. Radiother Oncol [Internet]. 2015 [cited 2015 Dec 9];114:73-8. Available from: http://www.ncbi.nlm.nih.gov/pubmed/25227961

37. Jones B, Dale RG, Finst $P$, Khaksar SJ. Biological equivalent dose assessment of the consequences of hypofractionated radiotherapy. Int J Radiat Oncol Biol Phys. 2000;47:1379-84.

38. Tsang Y, Haviland J, Venables K, Yarnold J, FAST Trial Management Group. The impact of dose heterogeneity on late normal tissue complication risk after hypofractionated whole breast radiotherapy. Radiother Oncol [Internet]. 2012 [cited 2014 Aug 26];104:143-7. Available from: http://www.ncbi.nlm.nih.gov/pubmed/ 22809586 
39. Irabor OC, Swanson W, Shaukat F, Wirtz J, Mallum AA, Ngoma T, Elzawawy A, Nguyen P, Incrocci L, Ngwa W. Can the Adoption of Hypofractionation Guidelines Expand Global Radiotherapy Access? An Analysis for Breast and Prostate Radiotherapy. JCO Glob Oncol. 2020 Apr;6:667-678. doi: 10.1200/JGO.19.00261.

40. Marta GN, Ramiah D, Kaidar-Person O, Kirby A, Coles C, Jagsi R, et al. The Financial Impact on Reimbursement of Moderately Hypofractionated Postoperative Radiation Therapy for Breast Cancer: An International Consortium Report. Clin Oncol [Internet]. Elsevier Ltd; 2020 [cited 2021 Feb 13];0. Available from: http://www.clinicaloncologyonline.net/article/S0936655520304842/fulltext

41. Cardoso F, MacNeill F, Penault-Llorca F, Eniu A, Sardanelli F, Nordström EB, et al. Why is appropriate healthcare inaccessible for many European breast cancer patients? - The EBCC 12 manifesto. Breast. Churchill Livingstone; 2021;55:128-35.

42. Khan AJ, Rafique R, Zafar W, Shah C, Haffty BG, Vicini F, et al. Nation-Scale Adoption of Shorter Breast Radiation Therapy Schedules Can Increase Survival in Resource Constrained Economies: Results From a Markov Chain Analysis. Int J Radiat Oncol [Internet]. 2017 [cited 2017 Jan 21];97:287-95. Available from: http://www.ncbi. nlm.nih.gov/pubmed/27986343 